\title{
Anna Turan Machado Falcão (1862-1940): a pioneira médica esquecida da Amazônia
}

\author{
Anna Turan Machado Falcão (1862-1940): the forgotten Amazonian pioneer doctor \\ Anna Turan Machado Falcão (1862-1940): la pionera médica olvidada de La Amazonía \\ Aristoteles Guilliod de Miranda \\ Instituto Histórico e Geográfico do Pará, Universidade Federal do Pará, \\ José Maria de Castro Abreu Jr. \\ Belém, Pará, Brasil

\begin{abstract}
Instituto Histórico e Geográfico do Pará, Universidade Federal do Pará, Belém, Pará, Brasil
\end{abstract}

\section{RESUMO}

O artigo esboça uma biografia de Anna Turan Machado Falcão. Nascida em 1862, em Igarapé Miri, Estado do Pará, foi a primeira médica paraense, formada em 1887, nos Estados Unidos da América. Após retornar ao Brasil e revalidar seu diploma na Faculdade de Medicina da Bahia, exerceu sua profissão no Pará, no Acre e em São Paulo, onde faleceu, em 1940.

Palavras-chave: História da Medicina; Mulher Médica; Amazônia; Pará.

Embora a instituição do ensino da medicina no Brasil* tenha acompanhado a chegada da família real portuguesa, em 1808, durante muito tempo não foi permitido que as mulheres frequentassem os cursos oferecidos no Brasil, os quais, por quase 100 anos a partir da sua instalação, se restringiram apenas às Faculdades da Bahia e do Rio de Janeiro.

Aquelas que desejavam seguir a profissão médica tinham que buscar a Europa - há relatos de mulheres exercendo a Medicina na Itália, França e Alemanha ${ }^{2,3}$ desde a Idade Média - ou os Estados Unidos, que, embora com restrições, contava, desde os meados dos anos 1800, com cursos médicos específicos para mulheres ${ }^{\dagger}$.

\section{Correspondência / Correspondence / Correspondencia:}

Aristoteles Guilliod de Miranda

Universidade Federal do Pará

Travessa 14 de Abril, 1716

CEP: 66063-140 Belém-Pará-Brasil

E-mail:ariguilliod@hotmail.com

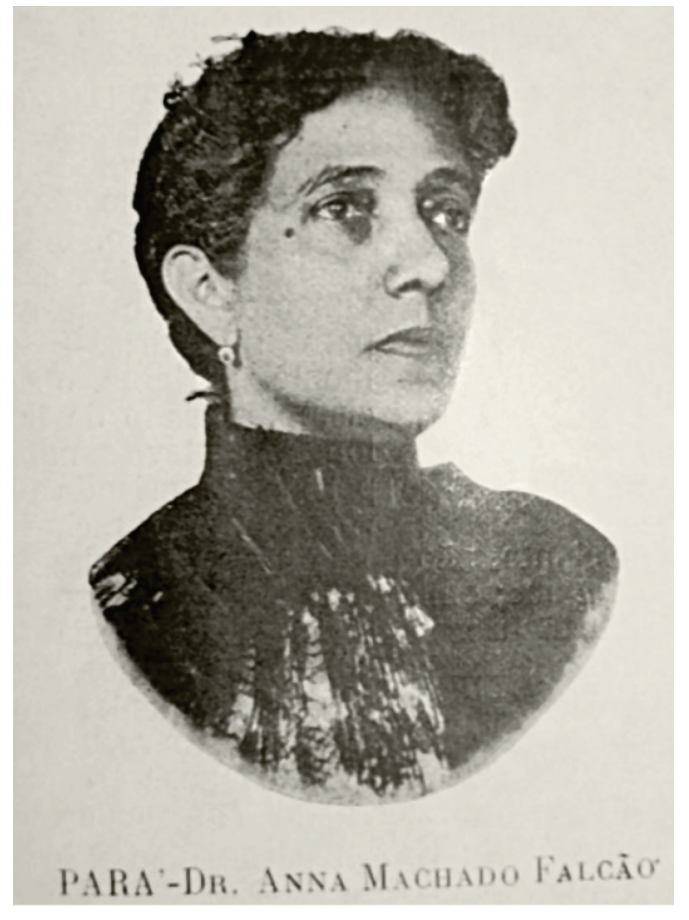

Fonte: A Revista do Norte 1903 out 1;(3):51.

Anna Turan Machado Falcão

\footnotetext{
* A ordem de criação das dez primeiras escolas médicas no Brasil é a seguinte: $1^{9}$ ) Salvador - Escola de Anatomia, Medicina e Cirurgia - fundada em 18 de fevereiro de 1808 ; transformada em Faculdade após 1832; atualmente ligada à Universidade Federal da Bahia. ${ }^{a}$ ) Rio de Janeiro - Escola de Anatomia, Medicina e Cirurgia - fundada em 5 de novembro de 1808; transformada em Faculdade após 1832, posteriormente Faculdade Nacional de Medicina da Universidade do Brasil; atualmente ligada à Universidade Federal do Rio de Janeiro. $3^{a}$ ) Porto Alegre - fundada em 25 de junho de 1898, início do curso em 1899; atualmente ligada à Universidade Federal do Rio Grande do Sul. $4^{a}$ ) Belo Horizonte - fundada em 5 de março de 1911, início do curso em 8 de abril de 1912; hoje integrada à Universidade Federal de Minas Gerais. $5^{a}$ ) Rio de Janeiro Faculdade de Medicina Homeopática do Rio de Janeiro, ou Faculdade Hahnemanniana - fundada em 1912, início do curso em $1^{\circ}$ de fevereiro de 1913; posteriormente Escola de Medicina e Cirurgia do Rio de Janeiro; hoje integrada à Universidade Federal do Estado do Rio de Janeiro. $6^{\circ}$ ) São Paulo - Faculdade de Medicina de São Paulo fundada em 19 de dezembro de 1912, início do curso em 2 de abril de 1913; atual Faculdade de Medicina da Universidade de São Paulo. 79a) Curitiba - Faculdade de Medicina do Paraná - fundada em 28 de outubro de 1913, início do curso em 13 de abril de 1914; atualmente ligada à Universidade Federal do Paraná. $8^{a}$ ) Belém Faculdade de Medicina do Pará - fundada em 9 de janeiro de 1919, início do curso em $1^{\circ}$ de maio de 1919; atualmente integrada à Universidade Federal do Pará. $9^{a}$ ) Recife Faculdade de Medicina do Recife - fundada em 5 de abril de 1915, início do curso em 16 de julho de 1920; atualmente integrada à Universidade Federal de Pernambuco. $10^{\circ}$ ) Niterói - Faculdade Fluminense de Medicina - fundada em 25 de junho de 1925, início do curso em 31 de maio de 1926; hoje integrada à Universidade Federal Fluminense

Elizabeth Blackell, a primeira a formar-se em medicina, pelo Geneva College, em New York, em 1849, e sua irmã Emily, inglesas emigradas para os Estados Unidos, fundaram inicialmente o New York Infirmary for Indigent Women and Children, em New York City, em 1853, o qual, a partir de 1864, foi autorizado a conferir diplomas de médicos para mulheres com o nome de Infirmary Medical School. Outra escola importante foi o New York Medical College and Hospital for Women, criada na cidade de New York por Clemence S. Lozier, em 1863 $3^{3,4}$.
} 
Mesmo impedidas de estudar no Brasil, as mulheres poderiam revalidar seus diplomas caso tivessem estudado no exterior. Ainda que pareça um contrassenso, era assim que as coisas funcionavam naqueles tempos. Somente com a Reforma Leôncio de Carvalho, instituída pelo Decreto $n^{\circ} 7.247$, de 19 de abril de 1879 ensino livre, é que as portas das faculdades brasileiras seriam abertas para as mulheres.

Um dos destinos mais frequentes para as brasileiras passou a ser os Estados Unidos, que contava, desde 1863, com uma Faculdade de Medicina exclusivas para mulheres ${ }^{\S}$.

O New York Medical College and Hospital for Women " foi o destino da carioca Maria Augusta Generoso Estrela, que ali se matriculou em 17 de outubro de 1876, com a idade de 16 anos, após submeter-se aos exames regulamentares. Maria Augusta concluiria seu curso em 1879, "abrindo as portas das faculdades de medicina para as mulheres", mas, por não ter a idade mínima necessária, teria que aguardar dois anos para receber seu diploma".

Maria Augusta, juntamente com a Josefa Águeda Oliveira** - outra brasileira - quando ambas ainda eram estudantes de medicina nos Estados Unidos, na mesma escola, editaram um jornal, em português, intitulado $A$ Mulher, lançado em 1881, e que se dizia um "Periódico llustrado de Literatura e Belas Artes, consagrado aos interesses e direitos da mulher brasileira", no qual propagavam a emancipação da mulher. $\bigcirc$ jornal teve grande repercussão no Brasil, sendo divulgado por meio da imprensa, recebendo críticas e apoio, que resultaram em discussões acaloradas a respeito do papel da mulher na sociedade ${ }^{6}$.

A saga de Maria Augusta Estrela - e porque não, de Josefa Águeda - chegou a Belém, por meio dos jornais, uma vez que o Diario do Gram-Pará, de 21 de janeiro de 1881, destacou o seguinte ${ }^{6}$ :

\footnotetext{
Com este titulo começou a ser publicado em New-York um periodico illustrado, consagrado aos interesses e direitos da mulher brazileira.

É uma revista de muito merecimento, e da maior ainda quando tem como redactoras as nossas distinctissimas patricias Maria A. Generoso Estrella e Josepha A.F. Mercedes de Oliveira estudantes de medicina naquella cidade.

A Mulher é, pois, jornal que se recommenda por todos os titulos, e, ao mesmo tempo, nos deve encher de justa satisfação por vel-o sob a intelligente direcção de duas jovens, que tão brilhantemente honram a sua patria no estrangeiro [...] É uma revista com capa, tem 8 paginas e gravuras; custa $5 \$$ por anno, pagos no acto da inscripção. (Grifo nosso)
}

Possivelmente o conhecimento da odisseia destas duas brasileiras fortaleceu em uma paraense o desejo de também estudar medicina: era Anna Turan Machado (Figura 1).

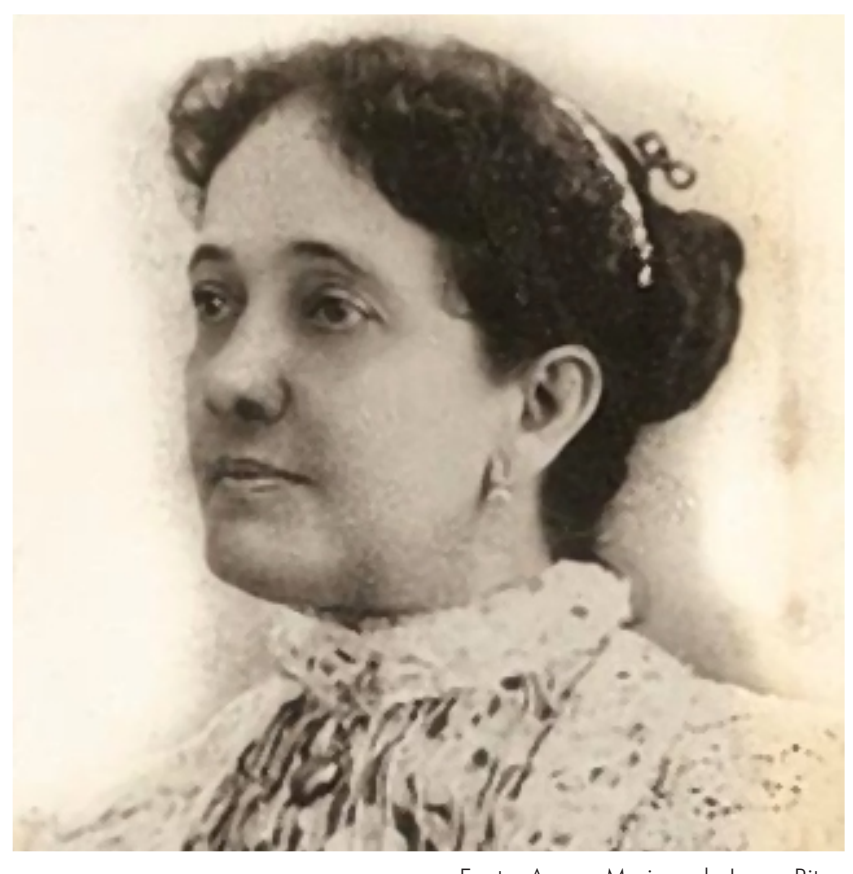

Figura 1 - Dra. Anna Turan

Nascida em Igarapé Miri, no engenho da família, em 28 de abril de 1862, filha de Antônio Lopes Machado e Andreza Turan, Anna era a mais velha de três irmãos: Maria Turan Machado e Antônio Lopes Machado Filho, para o qual o pai desejava o estudo da medicina. Ocorre que o jovem Antônio não era chegado aos estudos, não conseguindo realizar o projeto de seu pai. Mas, para que o desejo de seu pai, senhor de engenho e proprietário de muitos escravos, pudesse ser realizado, Anna decidiu que ela seria a médica. E assim, em 1882, ela partiu para Nova lorque, para a mesma faculdade em que as outras brasileiras haviam estudado, acompanhada de seu pai e de sua irmã, Maria, que lá permaneceu, estudando piano no conservatório.

Após cinco anos de estudo, Anna formou-se em 19 de abril de 1887, em uma turma composta por dez mulheres. A cerimônia de colação de grau da New York Medical College and Hospital for Women não acontecia nas dependências da Faculdade, "por não poder conter o número das pessoas de amizade e dos curiosos que costumam a concorrer nessas ocasiões" ${ }^{16}$. $\bigcirc$ local para a solenidade era o Association Hall de Nova lorque. $\bigcirc$

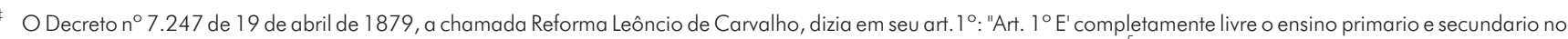
municipio da Côrte e em todo o Imperio, salvo a inspecção necessaria para garantir as condições de moralidade e hygiene ${ }^{11^{5}}$.

$\S$ Em meados do século XIX, existiam, nos Estados Unidos, dois tipos de escolas médicas: as "regulares", ou seja, oficiais, e as "irregulares", ou "sectárias", por estarem ligadas a seitas religiosas. Estas escolas não oficiais admitiam mulheres, embora o nível do ensino deixasse a desejar ${ }^{3}$.

"O New York Medical College and Hospital for Women foi criado por um ato especial da legislação, associada ao New York Medical College, em 14 de abril de 1863, por Clemence Sophia Losier, pioneira que tornou possível às mulheres estudarem medicina naquele País. Esta escola médica funcionou até 1918 , quando foi incorporada à Universidade de New York ${ }^{4}$.

" Maria Augusta Estrela seria a primeira mulher brasileira a graduar-se em medicina. Sua formatura aconteceu em 29 de março de 1881 , juntamente com mais três colegas, sendo a brasileira a oradora da turma. Sua tese denominou-se "Moléstias da pele"

** Josefa Águeda Felisbela Mercedes de Oliveira, pernambucana nascida em 1864, estudou no New York Medical College and Hospital for Woman até o terceiro ano de medicina, retornando ao Brasil em fins de 1882, por problemas de saúde. Não chegou a formar-se em medicina, mantendo-se ministrando aulas de francês, inglês, espanhol, anatomia descritiva, fisiologia e "algumas outras matérias tendentes à medicina, em troca de alguma gratificação" ${ }^{6}$. Rago dá a seguinte informação: "Formada em 1881, no mesmo ano em que se diplomou Maria Augusta Generoso Estrela, não há dados que mostrem sua trajetória depois do seu retorno ao Recife".
} 
edifício foi magnificamente iluminado, enfeitado com flores e com bandeiras norte-americanas - e, neste caso, certamente com brasileiras, por conta da formanda -, e contou com uma banda de música para abrilhantar o evento. Prestigiaram a solenidade os professores, médicos e médicas, as alunas e familiares e amigos.

De acordo com o protocolo, após a prece inicial era feita a leitura dos relatórios anuais da escola, seguida pelos discursos dos oradores. $\mathrm{Na}$ sequência, as formandas prestavam o juramento de Hipócrates e recebiam os diplomas ${ }^{\dagger \dagger}$. Por seu brilhante desempenho na faculdade, sendo a primeira aluna da turma, Anna receberia uma medalha de honra ao mérito, de ouro ${ }^{8}$, aposta ao diploma (Figura 2).

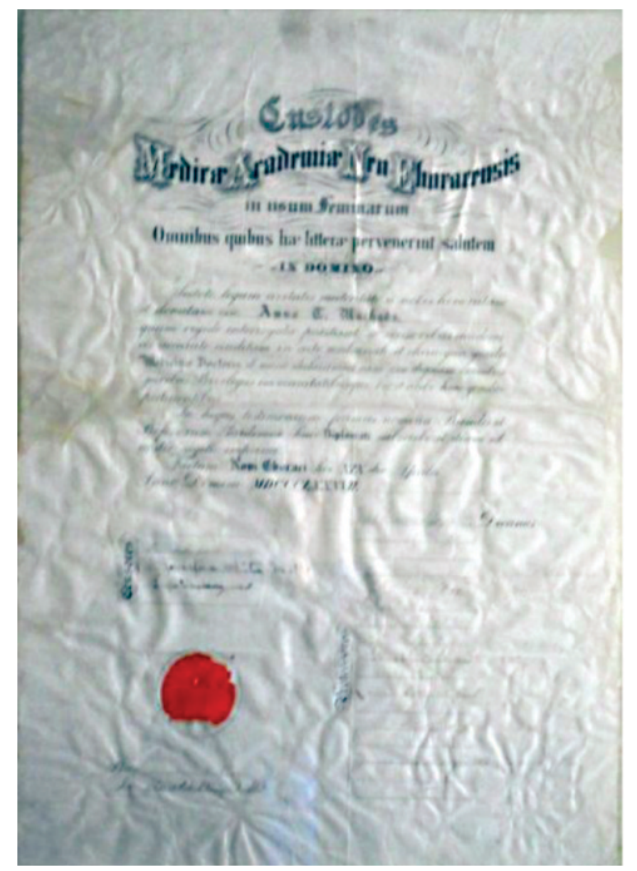

Fonte: Acervo Mariangela Lopes Bitar.

Figura 2 - Diploma da Dra. Anna

Ao retornar ao Brasil, Anna teria que revalidar seu diploma na Bahia ou no Rio de Janeiro, mas antes passaria em sua terra natal, para as comemorações ao lado da família. A festa de recepção, uma grande festa organizada por seu pai, seria interrompida para que ela fosse atender uma de suas escravas que, em trabalho de parto, necessitava de seus conhecimentos?.

Então, Anna partiu para Salvador, a fim de ter seu diploma revalidado pela Faculdade de Medicina da Bahia, a qual, em 10 de dezembro daquele ano de 1887 veria formada a sua primeira médica: Rita Lobato Velho Lopes $^{2}$. O contato entre elas seria registrado nas homenagens prestadas por Rita em sua tese de doutoramento, em que a "Dra. Anna Tourão Machado" é incluída entre as "minhas simpáticas colegas", juntamente a três outras médicas e uma provável estudante ${ }^{6}$. Ressalte-se que Anna foi a primeira mulher a fazer o exame de habilitação na Faculdade de Medicina da Bahia, para a revalidação do diploma ${ }^{10}$, conforme a nova legislação, sendo a revalidação concedida em 28 de janeiro de 1892, conforme consta no Livro de Registro de Diplomas (1890/1897, p. 31-32) da referida Faculdade" .

\begin{abstract}
Registro da apostilla da $\operatorname{Dr}^{\mathrm{a}}$ Anna T. Machado. Considerada habilitada ao exercício da profissão nos Estados Unidos do Brazil, na forma dos Estatutos das Faculdades de Medicina da Republica. Bahia e Faculdade de Medicina 28 de janeiro de 1892. $O$ director da Faculdade Dr ${ }^{\circ}$. Antonio Cerqueira Pinto. 0 secretario Dr ${ }^{\circ}$. Alessandro (?) dos Reis Meirelles Pinto. $N^{\circ} 2 R \$ 200 \$ 000$. Pagou duzentos mil reis de sello. Alfândega da Bahia, 28 de janeiro de 1892.
\end{abstract}

A revalidação do diploma implicaria em mais dois anos de estudos para Anna Turan Machado. A estada na Bahia permitiu que a jovem médica conhecesse Emilio Ambrósio Marinho Falcão (Figura 3), jovem estudante pernambucano, com quem viria a casar. Entretanto, a morte de seu pai interrompeu a temporada de estudos, fazendo com que Anna voltasse para lgarapé Miri, para cuidar das coisas da família. Ao retomar os estudos, na Bahia, três anos depois, Anna estva casada com Emilio A. Marinho Falcão, já formado cirurgião dentista, e grávida da primeira das cinco filhas que teria. Emilio estudava medicina na Faculdade de Medicina da Bahia quando a conheceu. Apaixonaram-se e ele, para poder casar mais rápido, trocou o curso para odontologia. Para revalidar seu diploma, além de complementar os estudos, Anna defenderia a tese "A Ovariotomia e suas indicações"12.

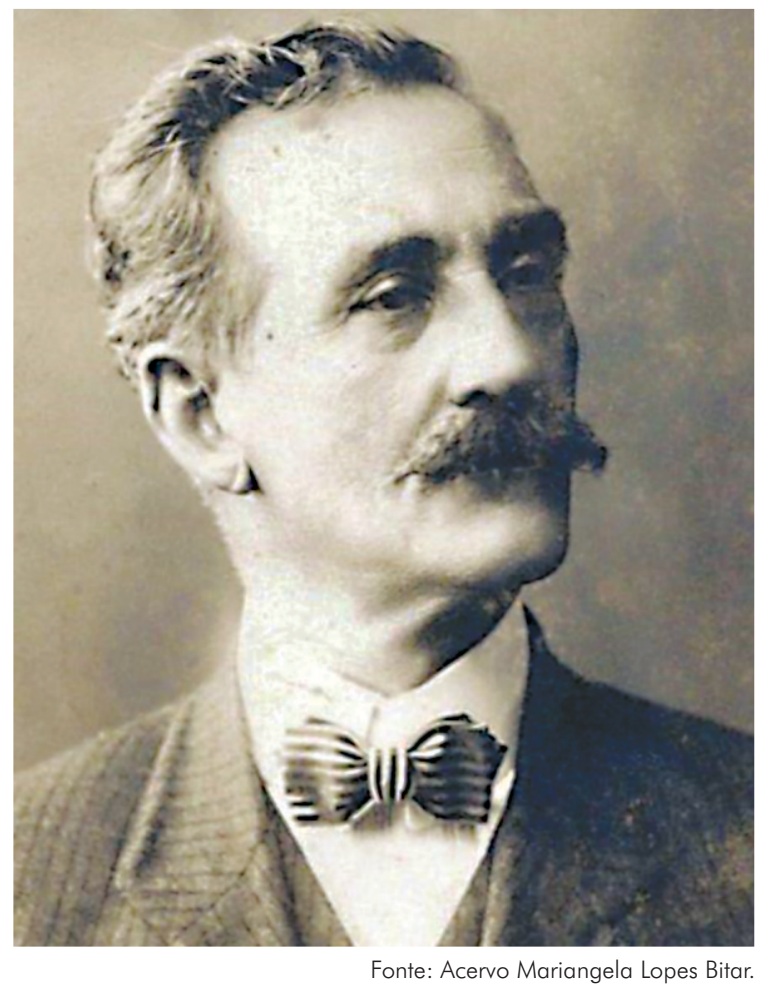

Figura 3 - Emilio Ambrósio Marinho Falcão

\footnotetext{
t† Baseado na descrição da cerimônia de colação de grau de Maria Augusta Generoso Estrela
} 
Em 1891, Anna passaria uns meses em Quixadá, no Ceará, acompanhando o marido, que buscara aquela cidade para tratamento de saúde. Ali também deixaria sua marca, relembrada com carinho e reconhecimento pelo vigário da cidade ${ }^{\ddagger}$, por conta da dedicação para com os pobres habitantes do local:

Ha factos na vida humana que nunca se esquecem, por que deixão no coração d'aquelles, que os presenciam traços verdadeiramente indeleveis.

Ha cerca de dois mezes que o Quixadá teve a ventura de receber-vos em seu seio, e desde então começou elle a conhecer de quanto era e é capaz vosso coração magnânimo e alma bemfazeja.

No exercício de vossa honrosa profissão seria bem difícil enumerar os bens que aqui fizestes. Ninguem a vós recorreu que não fosse attendido. A vossa promptidão em acodir a qualquer chamado, ora soffrendo em sol ardente, ora sahindo a horas mortas da noute, quer para a casa do rico, quer para a choupana do pobre, levantou tão alto o vosso nome n'esta cidade que jamais será esquecido.

Vós, durante o curto período de tempo que aqui vos demorastes, fostes o Anjo de bondade que veio derramar o balsamo de consolação entre a pobreza desvalida que absorta vos contemplava como sua mais desvelada protectora.

E o que mais vos elevou no conceito de todos, principalmente dos pobres era o modo por que tratáveis a todos: nunca tivestes para com os enfermos senão palavras de carinho, vossa afabilidade, vossa ternura e dedicação para com elles bem depressa captaram a confiança de todos que extasiados se admiravam de tantos predicados reunidos, formando este admiravel complexo que se chama Doutora Anna Machado Falcão.

Exma. Sra., em nome do povo do Quixadá e especialmente da pobreza desvalida de quem sou humilde Pastor, venho, neste momento solemne, agradecer-vos os immensos beneficios que aqui fizestes; venho manifestar-vos meus sentimentos de pesar pela vossa retirada d'esta cidade, theatro onde se expandio vosso coração sempre aberto a todas as dores, e a todas as miserias.

Desculpe Exma. Sra. esta singela, mas sincera manifestação de apreço toscamente elaborada, que, neste momento, vos dirige o Parocho da Freguesia interprete dos sentimentos de seus parochianos.

Quixadá, 22 de junho de 1891

$\bigcirc$ Vigario Antonio Alexandrino de Alencar

Se o propósito da estada no Ceará era o de descansar para reiniciar a vida, após a cansativa temporada de estudos na Bahia, decerto isto não foi alcançado.

Com o término dos estudos, a defesa da tese (Figura 4) e a consequente revalidação do diploma, Anna está pronta para exercer sua profissão no Pará. Ao retornar para Belém, em 1892, a região vivia os áureos tempos da borracha, mas vivia também dias atribulados em sua política. E Anna, intitulando-se "especialista em moléstias das senhoras" e "aceitando chamados a qualquer hora do dia ou da noite" abre consultório à Rua 13 de maio, 59, juntamente com seu marido, que ali também tem seu "gabinete de cirurgia e prothese dentaria" ${ }^{113}$ (Figura 5).

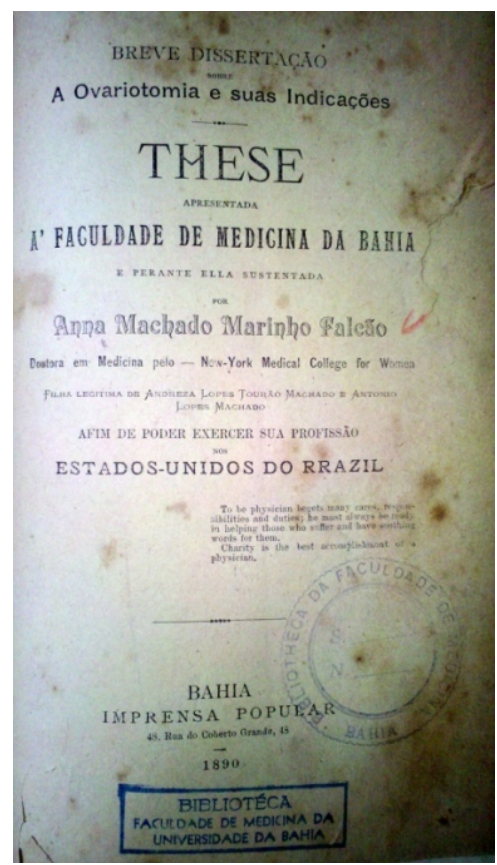

Figura 4 - Tese para revalidação do diploma defendida na Faculdade de Medicina da Bahia

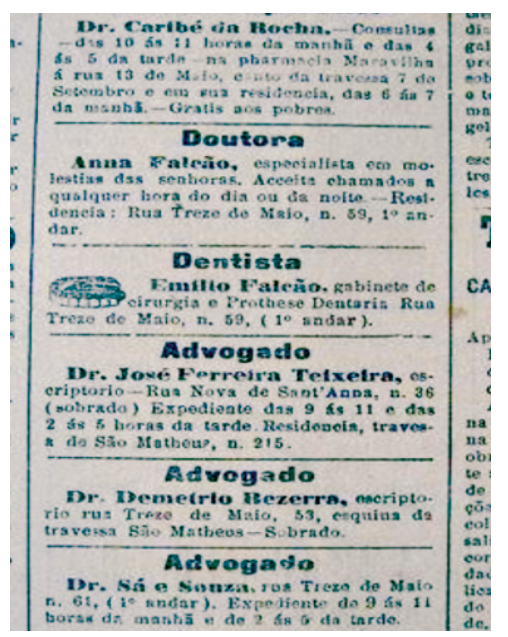

Figura 5 - Anúncio dos serviços da Dra. Anna Falcão publicado no Jornal do Commercio, 24 de julho de 1904

Emilio teria entre seus muitos clientes o célebre compositor Carlos Gomes. Já com câncer na língua, nenhum profissional queria atendê-lo. Emilio, com sua habilidade e capacidade, extraiu-lhe um dente e obteve sucesso. Em agradecimento, Carlos Gomes escreveu-lhe uma carta acompanhada de uma fotografia. Hoje, esta relíquia faz parte do acervo do Museu do Tribunal de Justiça de São Paulo, doada pelo seu neto, desembargador Marino Emílio Falcão Lopes ${ }^{\S \S}$.

Tendo se envolvido em política, Emilio Falcão acabou sofrendo ameaças. Descontente com os rumos da política, arrendou o seringal "Aquidabam", no Acre, uma vasta extensão às margens do rio Acre (Figura 6), e partiu para lá em 1908, deixando a família em Belém.

\footnotetext{
¥ Correspondência do arquivo pessoal de Mariangela Lopes Bitar, bisneta de Anna e Emilio Machado Falcão.

§§ Informação de Ilka Falcão Lopes Bitar, neta de Anna e Emilio Machado Falcão.
} 


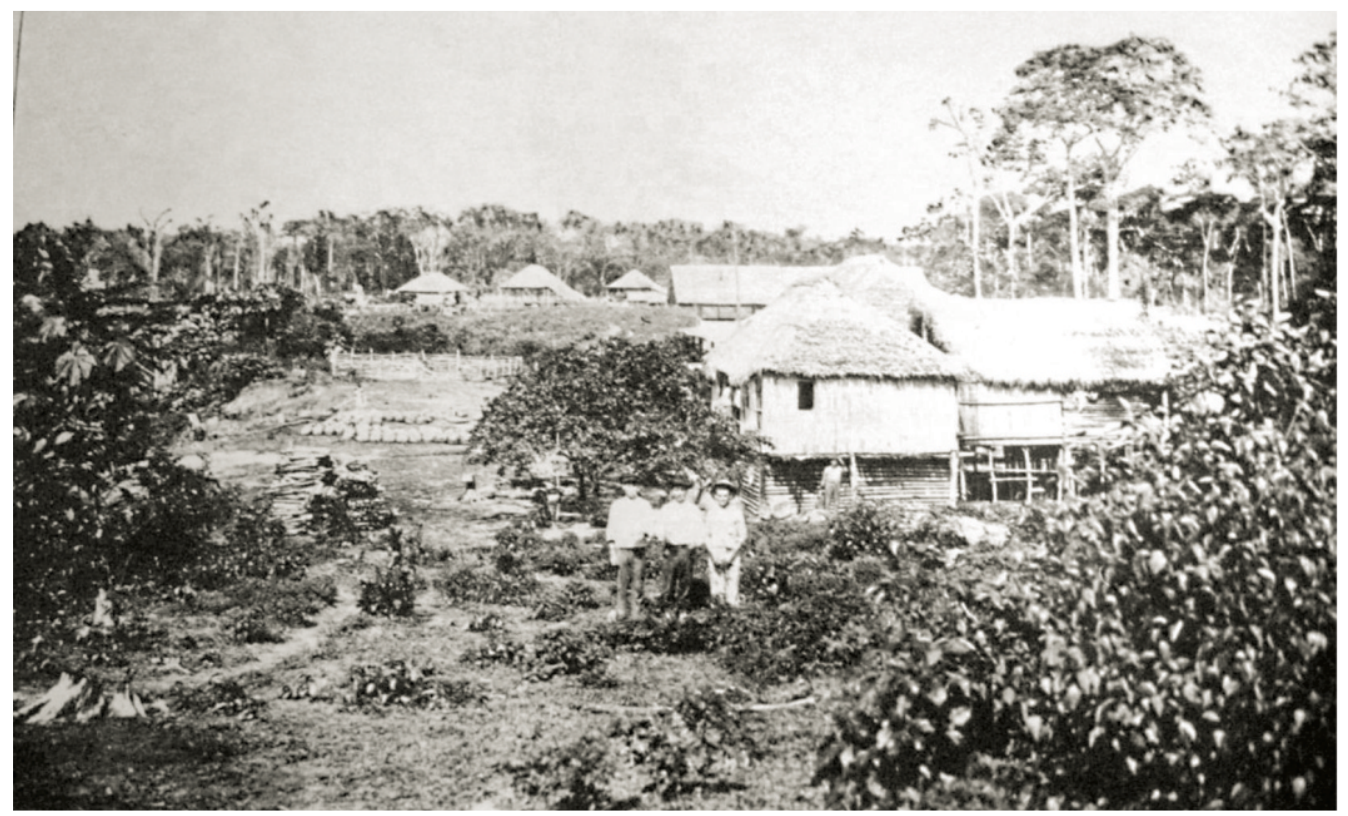

Fonte: Falcão E. Album do rio Acre. 1906-1907. Edição fac-similada, 1985. p. 136.

Figura 6 - Seringal Aquidabam

Anna ficou sem notícias de Emilio por quase um ano, até que ele regressou a Belém, em 1909. A decisão iá estava tomada por Anna: iriam todos para o seringal no Acre.

A viagem até o "Aquidabam" duraria 26 dias, a bordo do navio "Indio do Brazil", (Figura 7) tendo o comandante que mudar sua rota habitual para descer do rio Amazonas para o Purus e deste para o rio Acre. Ao desembarcarem no pequeno porto do seringal, o primeiro trabalho da médica, além de lavar toda a roupa suja acumulada pela longa viagem, foi cuidar da filha mais velha e da babá da filha caçula, que haviam adoecido, vindo esta última a falecer.
Agora, em plena floresta, tudo dependeria de sua habilidade no combate às doenças, como a malária, endêmica na região, e o surto de gripe espanhola, que chegaria até aquele longínquo rincão, provavelmente carreada pelas levas migratórias dos nordestinos que iam trabalhar nos seringais. Ela se abriga, com toda a família, inicialmente num barracão de madeira sobre palafitas, com escadas feitas de paus roliços e assoalhos de paxiúba, construído por Emilio juntamente com os seringueiros, e que as filhas chamam de brig firme. Ali Anna fabricaria os remédios obtidos da natureza. Ali seria a médica, a enfermeira, a parteira, tudo. Só não a paciente, porque conseguiria passar incólume às doenças.

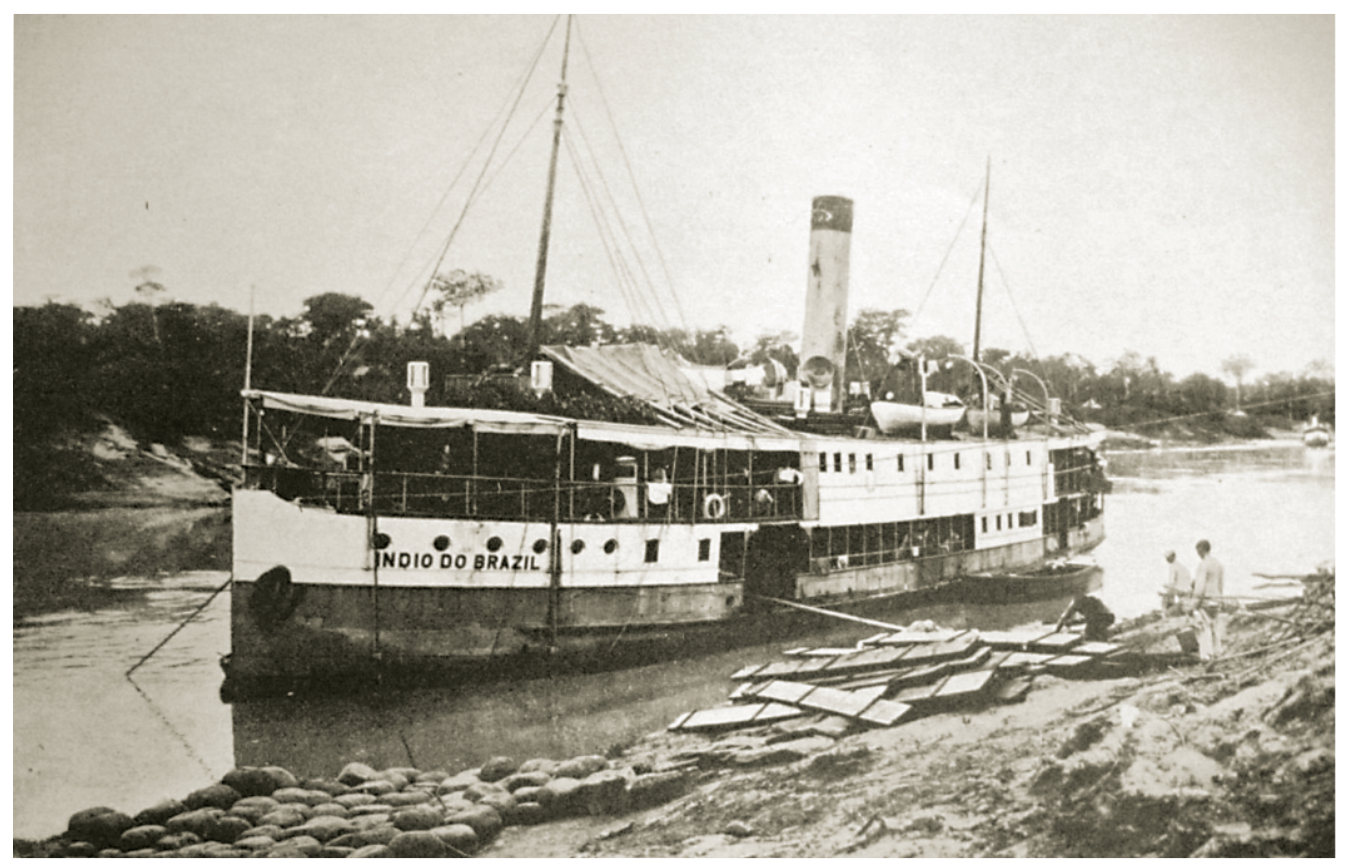

Figura 7 - Vapor Indio do Brazil 
Passado o período inicial, de maiores sacrifícios, Emilio constrói um sobrado de madeira, mais caprichado, com um armazém na parte térrea, ficando em cima o escritório, a farmácia da esposa e os quartos do casal e das filhas. No seringal viveriam a dra. Anna e sua família por mais de dez anos. Ali, as lanchas e batelões que navegavam pelo rio Acre levariam notícias sobre as cinco moças do seringal e, consequentemente, trariam os pretendentes.

Em 1921, com todas as filhas casadas, com advogados ou comerciantes, Anna e o marido se mudariam para Xapuri, a cidade mais próxima e, ainda assim, distante do seringal seis horas de barco, e onde a médica continuaria a exercer sua profissão. Naquela cidade, Emilio construiria uma casa, que seria chamada de
"Valcamber" (sigla alusiva às iniciais dos nomes das pessoas da família: Valdomira (segunda filha), Anna, Luciola (quinta filha), Celina (primeira filha), Ambrozina (quarta filha), Maria José (terceira filha), Bruno (genro), Emilio e Rolando (primeiro neto). A casa existe até hoje e é tombada ${ }^{|l| l}$.

Mas os genros advogados queriam progredir profissionalmente. Então, a filha mais velha - Celina - e a mais nova - Lucíola - acompanham seus maridos para São Paulo (Figura 8). Logo em seguida, em 1925, a médica e seu marido partem também para São Paulo, radicando-se em Santos, tendo ali a dra. Anna, já com 63 anos, realizado seu último trabalho como médica: assistência a um parto.

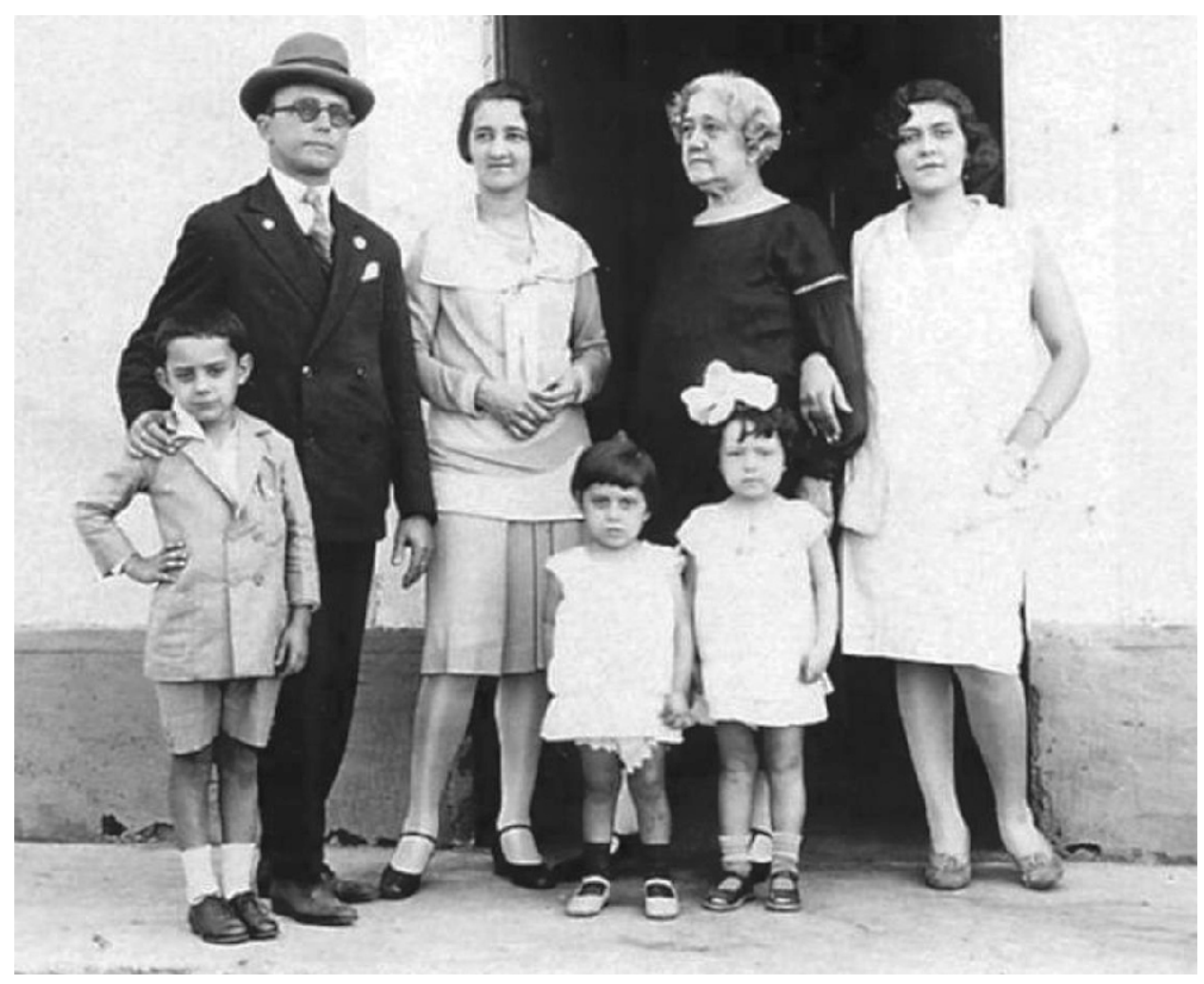

Fonte: Acervo Mariangela Lopes Bitar.

Figura 8 - Anna Turan já idosa (de negro), por volta de 1930, quando visitava sua filha Lucy em Cananéia, São Paulo

Mas o último grande exemplo da personalidade marcante da dra. Anna Machado Falcão aconteceria pouco tempo depois. Por ocasião da Revolução Constitucionalista de 1932, Anna, doaria para a causa sua aliança e a medalha de ouro aposta em seu diploma. Esta medalha, mais que um simples símbolo, era parte de sua vida. Em seu lugar, no diploma, fica um lacre vermelho. Anna contava então com 70 anos de idade?

A dra. Anna Turan Machado Falcão faleceu em 1940, aos 77 anos de idade, em São Paulo. No Acre, uma escola perpetua o nome desta pioneira da medicina brasileira. É muito pouco para quem tanto fez pelo engrandecimento da profissão médica. A Amazônia esperaria até 31 de dezembro de 1928 para ter sua primeira médica formada por uma escola da região: seria a dra. Olga Paes de Andrade, que colaria grau naquela data pela então Faculdade de Medicina e Cirurgia do Pará ${ }^{14}$.

\section{AGRADECIMENTOS}

À Mariangela Lopes Bitar e seus familiares, pelas informações, fotos e documentos. A Thiago Vianna, pelas pistas sobre "A Revista do Norte".

IIII Informação de Ilka Falcão Lopes Bitar, neta de Anna e Emilio Machado Falcão. 


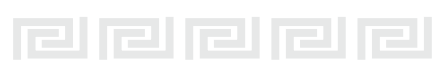

\section{Anna Turan Machado Falcão (1862-1940): the forgotten Amazonian pioneer doctor ABSTRACT}

This article outlines a biography of Anna Turan Machado Falcão. Born in 1862 in Igarapé-Miri, Pará State, Brazil, Dr. Anna Turan was Pará's first physician. She graduated in the United States of America in 1887. After returning to Brazil and validating her diploma at the Faculdade de Medicina da Bahia, she worked in the states of Pará, Acre and São Paulo, where she died in 1940.

Keywords: History of Medicine; Woman Doctor; Amazônia; Pará.

\section{Anna Turan Machado Falcão (1862-1940): la pionera médica olvidada de La Amazonía RESUMEN}

El artículo esboza una biografía de Anna Turan Machado Falcão. Nacida en 1862, en Igarapé Miri, Estado de Pará, fue la primera médica paraense, recibida en 1887, en los Estados Unidos de América. Después de retornar a Brasil y revalidar su diploma en la Facultad de Medicina de Bahia, ejerció su profesión en Pará, en Acre y en São Paulo, en donde falleció en 1940.

Palablas claves: Historia de la Medicina; Mujer Médica; Amazônia; Pará.

\section{REFERÊNCIAS}

1 Sarinho CT. Faculdades de Medicina do Brasil (As dez mais antigas): resumo histórico. Natal: Nordeste Gráfica; 1989.

2 Silva A. A primeira médica do Brasil. Rio de Janeiro: Irmãos Pongetti; 1954. 246 p.

3 Dall'ava-Santucci J. Mulheres e médicas: as pioneiras da medicina. Lencastre HS, tradutor. Rio de Janeiro: Ediouro; 2005. 245 p.

4 Cazalet S. History of the New York Medical College and Hospital for Women [Internet]. 2011 [cited 2011 Ago 24]. Available from: http://www.homeoint.org/ cazalet/histo/newyork.htm.

5 Brasil. Palácio do Rio de Janeiro. Decreto n 7.247, de 19 de Abril de 1879 [Internet]. Rio de Janeiro; 1879. p. 196 (Coleção de Leis do Império do Brasil). [acesso 2010 fev 25]. Disponível em: http://www2.camara. gov.br/internet/legislacao/legin.html/textos/ visualizarTexto. $h t m l$ ? ideNorma $=547933 \&$ seqTexto $=$ 62862\&PalavrasDestaque.

6 Capuano Y. Matris Anima Curant: as pioneiras médicas: Maria Augusta Estrela e Rita Lobato. São Paulo: Línea Médica Editorial; Scortecci Editora; 2002. $208 \mathrm{p}$.
7 Rago EJ. A ruptura do mundo masculino da medicina: médicas brasileiras no século XIX. Cad Pagu [Internet]. 2000 [citado 2011 ago 29];(15):199-225. Disponível em: http://www.bibliotecadigital.unicamp.br/ document/? down $=51347$.

8 Unicred News. Fala: em algum lugar do passado [Internet]. São Paulo; 2009 [citado 2010 fev 28]. Disponível em: http://www.unicredmetropolitana.com .br/unicrednews. php?idun $=210$.

9 O Estado de São Paulo 1972 jul 7, segunda-feira.

10 Castro D. A mulher submissa. Salvador: [editora desconhecida]; $220 \mathrm{p}$.

11 Vanin IM. As damas de branco na biomedicina baiana (1879-1949): médicas, farmacêuticas e odontólogas [tese]. Salvador (BA): Universidade Federal da Bahia, Salvador; 2008.275 p.

12 Meirelles NS, Santos FC, Oliveira VLN, Lemos Júnior $L P$, Tavares Neto J. Teses doutorais de titulados pela Faculdade de Medicina da Bahia, de 1840 a 1928. GM Bahia. 2004 jan-jun;74(1):9-101.

13 Jornal do Commercio 1904 jul 7;1 (201):3.

14 Miranda AG, Abreu Júnior JMC. Memória histórica da Faculdade de Medicina e Cirurgia do Pará, 1919. 1950: da fundação à federalização. Belém; 2009. p. 279. 